\title{
Hydrogen storage and distribution systems
}

\author{
Andreas Züittel
}

Received: 27 June 2003/ Accepted: 17 September 2003

(C) Springer Science+Business Media B.V. 2007

\begin{abstract}
Hydrogen storage and transportation or distribution is closely linked together. Hydrogen can be distributed continuously in pipelines or batch wise by ships, trucks, railway or airplanes. All batch transportation requires a storage system but also pipelines can be used as pressure storage system. Hydrogen exhibits the highest heating value per weight of all chemical fuels. Furthermore, hydrogen is regenerative and environment friendly. There are two reasons why hydrogen is not the major fuel of toady's energy consumption: First of all, hydrogen is just an energy carrier. And, although it is the most abundant element in the universe, it has to be produced, since on earth it only occurs in the form of water. This implies that we have to pay for this energy, which results in a difficult economic task, because since the industrialization we are used to consuming energy for free. The second difficulty with hydrogen as an energy carrier is the low critical temperature of $33 \mathrm{~K}$, i.e. hydrogen is a gas at room temperature. For mobile and in many cases also for stationary applications the volumetric and gravimetric density of hydrogen in a storage system is crucial. Hydrogen can be stored by six different methods and phenomena: high pressure gas cylinders (up to 800 bar), liquid hydrogen in cryogenic tanks (at $21 \mathrm{~K}$ ), adsorbed hydrogen on materials with a large specific surface area (at $T<100 \mathrm{~K}$ ), absorbed on interstitial sites in a host metal (at ambient pressure and temperature), chemically bond in covalent and ionic compounds (at ambient pressure), oxidation of reactive metals e.g. $\mathrm{Li}, \mathrm{Na}, \mathrm{Mg}, \mathrm{Al}, \mathrm{Zn}$ with water. These metals easily react with water to the corresponding hydroxide and liberate the hydrogen from the water. Finally, the metal hydroxides can be thermally reduced to the metals in a solar furnace.
\end{abstract}

Keywords Hydrogen $\cdot$ Metal hydride $\cdot$ Synthetic fuel $\cdot$ Storage

\footnotetext{
A. Züttel (ه)

Department of Environment, Energy and Mobility, Abt. 138 "Hydrogen \& Energy", EMPA Materials Sciences and Technology, Überlandstrasse 129,

Dübendorf 8600, Switzerland

e-mail: andreas.zuettel@empa.ch
} 


\section{Introduction}

Hydrogen storage and transportation or distribution is closely linked together. Hydrogen can be distributed continuously in pipelines or batch wise by ships, trucks, railway or airplanes. All batch transportation requires a storage system but also pipelines can be used as pressure storage system.

The world energy consumption increased from $5 \times 10^{12} \mathrm{kWh}^{-1} \mathrm{r}^{-1}$ in 1860 to $1.4 \times 10^{14} \mathrm{kWh}$ year $^{-1}$ today. More than $1.2 \times 10^{14} \mathrm{kWh}$ year $^{-1}(80 \%)$ are based on fossil fuels (coal, oil and gas). The population of human beings increased during the last century by a factor of 6 but the energy consumption by a factor of 80 (Magazin der Eidgenössischen Technischen Hochschule 2000). The worldwide average continuos power consumption today is $2 \mathrm{~kW} /$ person. In the USA the power consumption is in average $10 \mathrm{~kW} /$ person and in Europe about $5 \mathrm{~kW} /$ person and two billion of people on earth do not consume any fossil fuels. Considering the historical development of the energy carriers towards hydrogen rich fuels and the necessity to avoid the carbon dioxide emission hydrogen is the energy carrier of the future:

$$
\left.\left.\mathrm{C}(\text { coal }) \rightarrow-\mathrm{CH}_{2}-(\text { oil }) \rightarrow \mathrm{CH}_{4} \text { (natural gas }\right) \rightarrow \mathrm{H}_{2} \text { (hydrogen }\right)
$$

The series also shows a development from a solid to a liquid and finally gas state energy carrier. It has been estimated that hydrogen makes up more than $90 \%$ of all the atoms or $75 \%$ of the mass of the universe (Weast 1976). Hydrogen is the most abundant element on earth, less than $1 \%$ is present as molecular hydrogen gas $\mathrm{H}_{2}$, the overwhelming part is chemically bound as $\mathrm{H}_{2} \mathrm{O}$ in water and some is bound to liquid or gaseous hydrocarbons. The renewable production of hydrogen by means of electrolysis consumes electricity, which is physically work. The chemical energy per mass of hydrogen $\left(39.4 \mathrm{kWh} \mathrm{kg}^{-1}\right)$ is 3 times greater than that of other chemical fuels, e.g. liquid hydrocarbons $\left(13.1 \mathrm{kWh} \mathrm{kg}^{-1}\right.$ ) (Weast 1976). In other words the energy content of $0.33 \mathrm{~kg}$ of hydrogen corresponds to the energy content of $1 \mathrm{~kg}$ of oil. The energy content of a fuel is usually called the heating value. The difference between the upper and the lower heating value is the enthalpy of vaporization of water according to the state of the water as a result of the combustion. For hydrogen the lower heating value is $33.3 \mathrm{kWh} \mathrm{kg}^{-1}$, and the upper heating value is $39.4 \mathrm{kWh} \mathrm{kg}^{-1}$.

There is a technical and an economic challenge to overcome before the hydrogen energy economy becomes reality. The technical challenge is the real time production, the safe and comfortable storage and the efficient combustion of hydrogen. In order to satisfy the world demand on fossil fuels, more than $5 \times 10^{12} \mathrm{~kg}$ hydrogen have to be produced per year. This is roughly 100 times the hydrogen production from today. The solar constant is $1.362 \mathrm{~kW} \mathrm{~m}^{-2}$ and approximately $50 \%$ of the solar radiation reach the surface of the earth. Photovoltaic systems have an efficiency of about $10 \%$, which is the same for the best biological systems based on the photosynthesis. Corn is one of the most efficient plants with a photo-conversion efficiency of about $10 \%$ (Campbell 1996). The photovoltaic cells are in the best case half of the time irradiated. Under these conditions about $541,000 \mathrm{~km}^{2}\left(90 \mathrm{~m}^{2} /\right.$ person $)$ covered with photovoltaic cells are necessary to produce the word energy consumption of today. This surface area corresponds to a square with a side length of $740 \mathrm{~km}$ (Fig. 1). The economic challenge is the costs of the hydrogen production. World economy today is based on free energy naturally stored sun energy in fossil fuels 


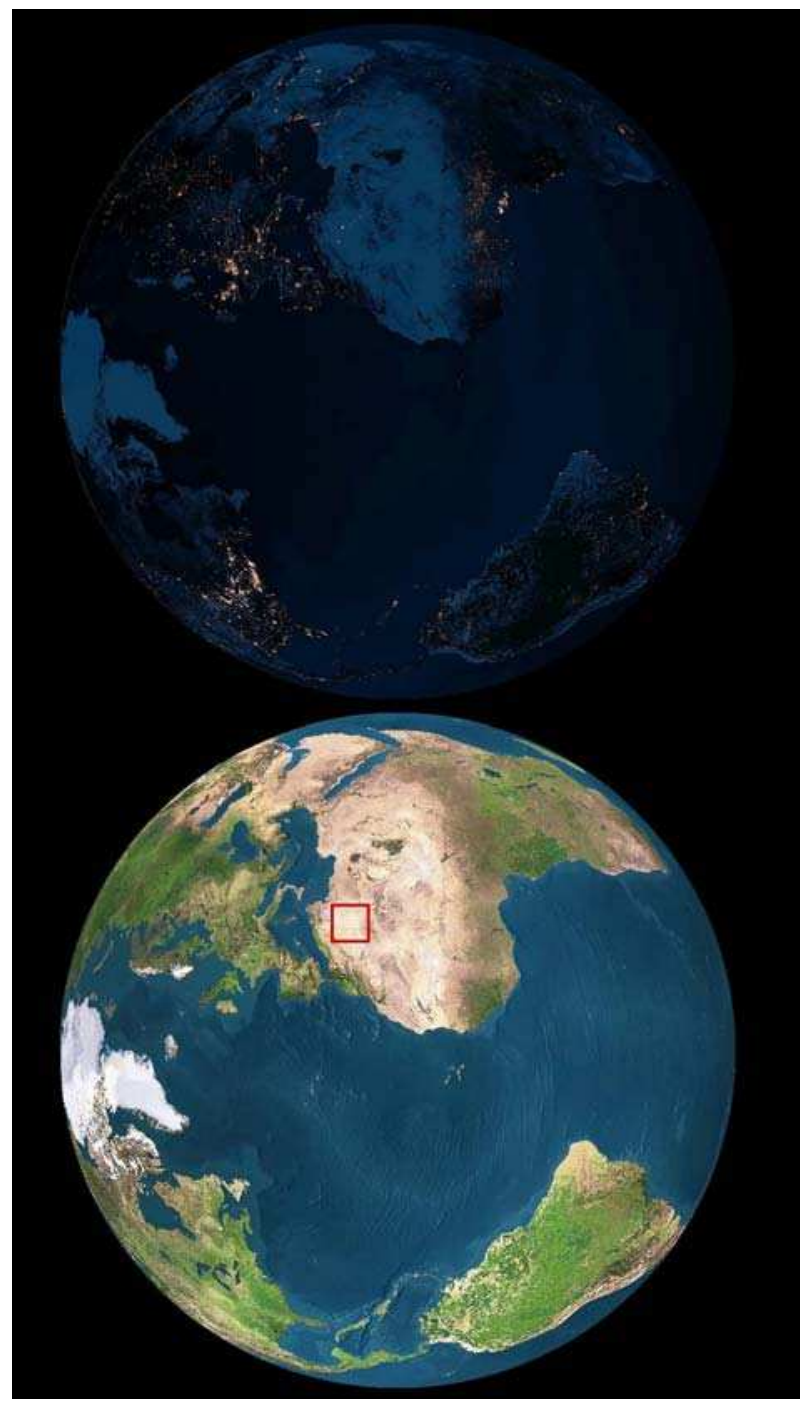

Fig. 1 Earth view with a square in the Sahara corresponding to the surface area necessary to be covered with photovoltaic cell in order to produce the world energy consumption of $1.6 \times 10^{14} \mathrm{kWh}$ year $^{-1}$. On the right-hand side earth view during the night showing the illuminated regions were energy is consumed

over millions of years. The price we are used to pay for fossil fuels is the mining and treatment cost only. In order to adapt the world to a synthetic fuel like hydrogen the world economy has to be convinced to pay for the energy content of the fuel too. The sun's energy is for free but the conversion of the sun's energy into an energy carrier e.g. biomass or electricity requires an investment. Renewable energy requires in general an investment of approximately 5 years the cost of the energy production. This means an investment of approximately $10^{13}-10^{14} €(1 € \approx 1$ US $\$$ ) or in words 10-100 trillion Euro, i.e. the same amount as is paid worldwide for renewable energy 
within 5 years. The investment corresponds to approximately $20 \%$ of the yearly income of a person in the highly industrialized countries.

The today worldwide consumed hydrogen as a chemical raw material (about $5 \times 10^{10} \mathrm{~kg} \mathrm{year}^{-1}$ ) is to a large extent produced using fossil fuels by means of the reaction $-\mathrm{CH}_{2} 4-+2 \mathrm{H}_{2} \mathrm{O} \rightarrow 3 \mathrm{H}_{2}+\mathrm{CO}_{2}$ at elevated temperature $\left(>850^{\circ} \mathrm{C}\right)$. This reaction consumes energy $8.9 \mathrm{kWh} \mathrm{kg}^{-1}$ hydrogen. However, the hydrogen production from fossil fuels is not renewable and produces at least the same amount of carbon dioxide as the direct combustion of the fossil fuel.

Hydrogen is a renewable fuel only if hydrogen is produced directly from solar light or indirectly via electricity from a renewable source e.g. wind power or hydro power. The direct thermal dissociation of $\mathrm{H}_{2} \mathrm{O}$ requires temperatures higher than $2,500^{\circ} \mathrm{C}$ (Steinfeld and Palumbo 2001). Furthermore, the thermal dissociation not only produces $\mathrm{H}_{2}$ but also atomic hydrogen and hydroxyl ions. This production method is therefore a subject of research activities and various problems e.g. the separation of hydrogen from oxygen, have to be solved before the thermal dissociation becomes a applicable method for the hydrogen production. Electricity from a renewable energy source, e.g. wind power, photovoltaics, hydropower and geothermal can be used for the electrolysis of water. Electrolysis at ambient temperature and ambient pressure requires a minimum voltage of $1.481 \mathrm{~V}$ and therefore a minimum energy of $39.7 \mathrm{kWh} \mathrm{kg}^{-1}$ hydrogen. Electrolyser systems today consume approximately $47 \mathrm{kWh} \mathrm{kg}^{-1}$ hydrogen, i.e. the efficiency is approximately $85 \%$ (GTec SA). Figure 2 shows the principle of the hydrogen cycle. The synthetic fuel

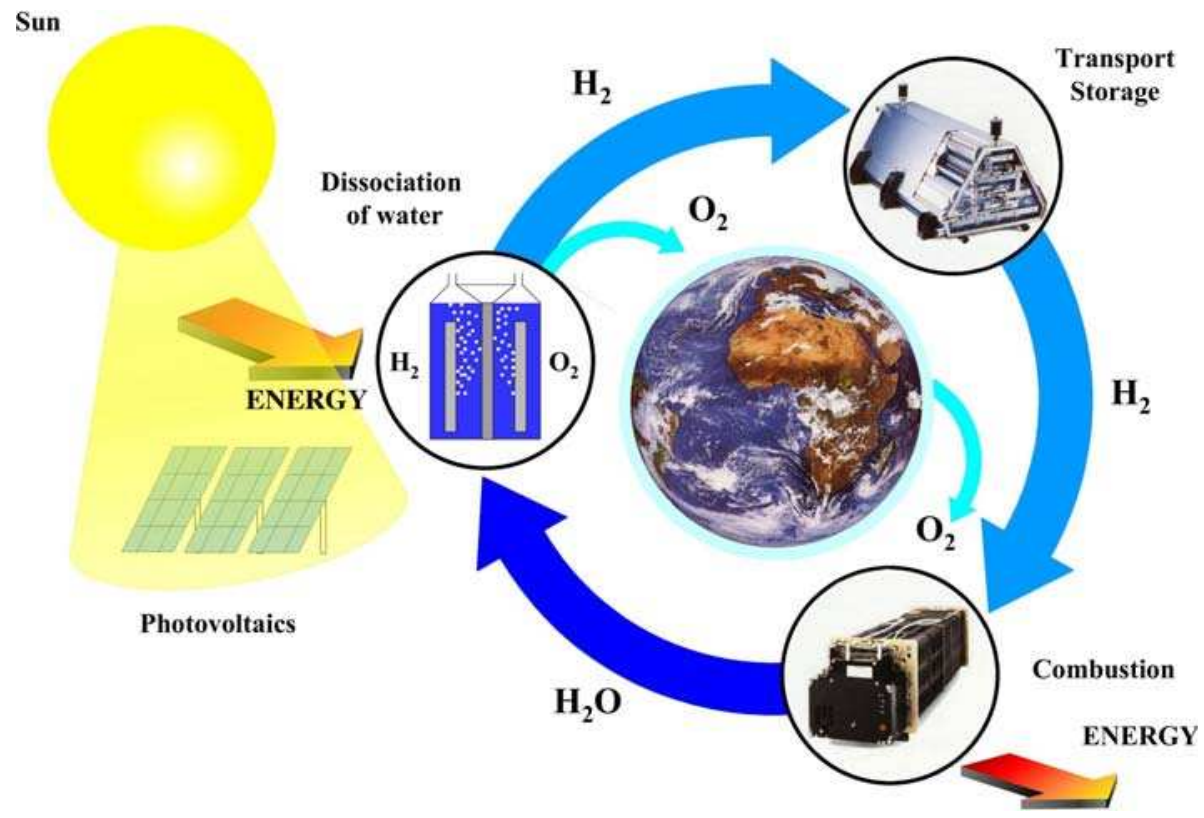

Fig. 2 The hydrogen cycle: The energy from the sunlight is converted into electricity by means of photovoltaic cells. The electricity is used to dissociate water into hydrogen and oxygen. The latter is released in the atmosphere and hydrogen is stored, transported and distributed. Finally, hydrogen together with the oxygen is combusted and the energy is released as work and heat leaving water or steam into the atmosphere. Therewith the hydrogen cycle is closed 
hydrogen is produced with the dissociation of water applying solar energy. The hydrogen is then stored and transported and finally combusted with air to form water and delivers the stored energy in form of work and heat.

Hydrogen can be transported in pipelines similar to natural gas. There are networks for hydrogen already operating today, a 1,500 km network in Europe and a $720 \mathrm{~km}$ network in the USA. The oldest hydrogen pipe network is in the Ruhr area in Germany now operated for more than 50 years. The tubes with a typical diameter of 25-30 cm are built using conventional pipe steel and operate at a pressure of 1020 bar. The volumetric energy density of hydrogen gas is $36 \%$ of the volumetric energy density of natural gas at the same pressure. In order to transport the same amount of energy the hydrogen flux has to be 2.8 times larger as compared to natural gas. However, the viscosity of hydrogen $\left(8.92 \times 10^{-6} \mathrm{~Pa} \mathrm{~s}\right)$ is significantly smaller than that of natural Gas $\left(11.2 \times 10^{-6} \mathrm{~Pa} \mathrm{~s}\right)$. The minimum power $P$ required to pump a gas through a pipe is given by

$$
P=8 \cdot \pi \cdot l \cdot v^{2} \cdot \eta
$$

where $l$ is the length of the pipe, $v$ the velocity and $\eta$ the dynamic viscosity of the gas. The transmission power per energy unit is therefore 2.2 times larger for hydrogen as compared to natural gas. The total energy loss for transportation of hydrogen is about $4 \%$ of the energy content. Because of the great length, and therefore the great volume of piping systems, a slight change in the operating pressure of a pipeline system results in a large change of the amount of hydrogen gas contained within the piping network. Therefore, the pipeline can be used to handle fluctuations in supply and demand, avoiding the cost of onsite storage.

\section{Hydrogen storage}

The ordinary isotope of hydrogen, $\mathrm{H}$ is known Protium and has an atomic weight of 1 (1 proton and 1 electron). The preparation of a stable isotope was announced in 1932, deuterium (D) with an atomic weight of 2 (1 proton and 1 neutron, 1 electron). Two years later an unstable isotope, tritium ( $\mathrm{T}$ ), with an atomic weight of 3 (1 proton and 2 neutron, 1 electron) was discovered. Tritium has a half-life of about 12.5 years (GTec SA). One atom of deuterium is found in about 6,000 ordinary hydrogen atoms $(0.017 \%)$. Tritium atoms are also present $10^{-18} \%$ (Baltimore 1998). All the isotopes of hydrogen react together and form, due to the single electron in the atom, covalent molecules like $\mathrm{H}_{2}, \mathrm{D}_{2}$ and $\mathrm{T}_{2}$, respectively. Hydrogen has a very ambivalent behavior to other elements, it occurs as anion $\left(\mathrm{H}^{-}\right)$or cation $\left(\mathrm{H}^{+}\right)$in ionic compounds, it participates with its electron to form covalent bonds e.g. with carbon, and it can even behave like a metal and form alloys at ambient temperature.

The hydrogen molecule $\mathrm{H}_{2}$ can be found in various forms depending on the temperature and the pressure which are shown in the phase diagram (Fig. 3). At low temperature hydrogen is a solid with a density of $70.6 \mathrm{~kg} \mathrm{~m}^{-3}$ at $-262^{\circ} \mathrm{C}$ and hydrogen is a gas at higher temperatures with a density of $0.09 \mathrm{~kg} \mathrm{~m}^{-3}$ at $0^{\circ} \mathrm{C}$ and a pressure of 1 bar. A small zone starting at the triple point and ending at the critical point exhibits the liquid hydrogen with a density of $70.8 \mathrm{~kg} \mathrm{~m}^{-3}$ at $-253^{\circ} \mathrm{C}$. At ambient temperature $(298.15 \mathrm{~K})$ hydrogen is a gas and can be described by the Van der Waals equation: 
Fig. 3 Primitive phase diagram for hydrogen (Leung et al. 1976). Liquid hydrogen only exists between the solidus line and the line from the triple point at $21.2 \mathrm{~K}$ and the critical point at $32 \mathrm{~K}$

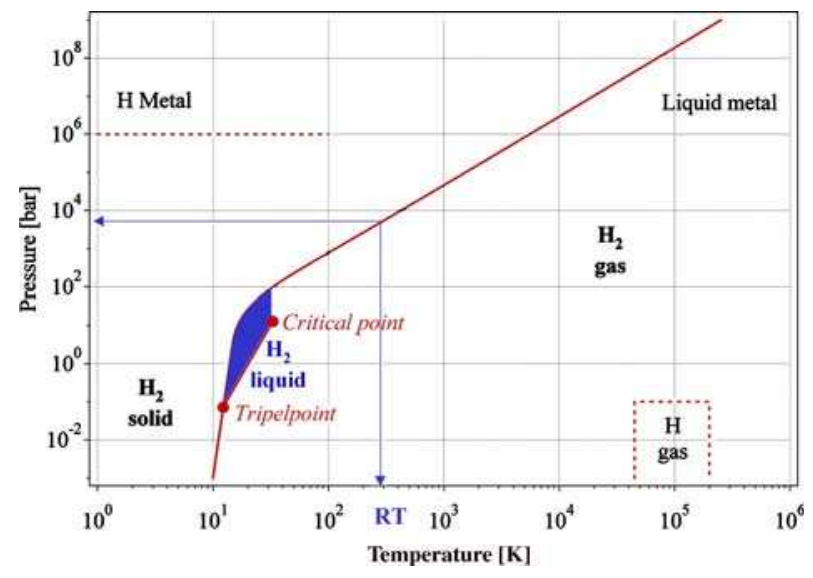

$$
p(V)=\frac{n \cdot r \cdot T}{V-n \cdot b}-a \cdot \frac{n^{2}}{V^{2}}
$$

where $p$ is the gas pressure, $V$ the volume, $T$ the absolute temperature, $n$ the number of mols, $R$ the gas constant $\left(R=8.314 \mathrm{~J} \mathrm{~K}^{-1} \mathrm{~mol}^{-1}\right)$, a is the dipole interaction or repulsion constant $\left(a=2.476 \times 10^{-2} \mathrm{~m}^{6} \mathrm{~Pa} \mathrm{~mol}^{-2}\right)$ and $b$ is the volume occupied by the hydrogen molecules itself $\left(b=2.661 \times 10^{-5} \mathrm{~m}^{3} \mathrm{~mol}^{-1}\right)$ (Weast 1976). The strong repulsion interaction between hydrogen molecules is responsible for the low critical temperature $\left(T_{\mathrm{c}}=33 \mathrm{~K}\right)$ of hydrogen gas. Hydrogen storage implies basically the reduction of the enormous volume of the hydrogen gas. One kilogram of hydrogen at ambient temperature and atmospheric pressure takes a volume of $11 \mathrm{~m}^{3}$. In order to increase the hydrogen density in a storage system either work can be applied to compress hydrogen or the temperature has to be decreased below the critical temperature or finally the repulsion has to be reduced by the interaction of hydrogen with an other material. The second important criterion for a hydrogen storage system is the reversibility of the hydrogen uptake and release. This criteria excludes all covalent hydrogen carbon compounds as hydrogen storage materials because the hydrogen is only released from carbon hydrogen compounds if they are heated to temperatures above $800^{\circ} \mathrm{C}$ or the carbon is oxidized. There are basically six methods in order to store hydrogen reversibly with a high volumetric and gravimetric density (Table 1). The following chapters focus on these methods and balance there advantages and disadvantages.

\subsection{High pressure gas cylinders}

The most common storage system are high pressure gas cylinders with a maximum pressure of $20 \mathrm{MPa}$. New light weight composite cylinders are developed which support pressure up to $80 \mathrm{MPa}$ and therefore, the hydrogen can reach a volumetric density of $36 \mathrm{~kg} \mathrm{~m}^{-3}$, approximately half as much as in its liquid form at the normal boiling point. The gravimetric hydrogen density decreases with increasing pressure due to the increasing thickness of the walls of the pressure cylinder. The wall 
Table 1 The six basic hydrogen storage methods and phenomena

\begin{tabular}{|c|c|c|c|c|c|}
\hline Storage methode & $\rho_{\mathrm{m}}(\operatorname{mass} \%)$ & $\rho_{\mathrm{V}}\left(\mathrm{kg} \mathrm{H}_{2} \mathrm{~m}^{-3}\right)$ & $T\left({ }^{\circ} \mathrm{C}\right)$ & $p$ (bar) & Phenomena and remarks \\
\hline High pressure gas cylinders & 13 & $<40$ & RT & 800 & $\begin{array}{l}\text { Compressed gas (molecular } \mathrm{H}_{2} \text { ) in light weight } \\
\text { composit cylinder (tensile strength of the } \\
\text { material is } 2,000 \mathrm{MPa} \text { ). }\end{array}$ \\
\hline Liquid hydrogen in cryogenic tanks & Size dep. & 70.8 & -252 & 1 & $\begin{array}{l}\text { Liquid hydrogen (molecular } \mathrm{H}_{2} \text { ), continuous loss } \\
\text { of a few \% per day of hydrogen at RT. }\end{array}$ \\
\hline Adsorbed hydrogen & $\approx 2$ & 20 & -80 & 100 & $\begin{array}{l}\text { Physisorption (molecular } \mathrm{H}_{2} \text { ) on materials e.g. } \\
\text { carbon with a very large specific surface area, } \\
\text { fully reversible. }\end{array}$ \\
\hline $\begin{array}{l}\text { Absorbed on interstitial sites } \\
\text { in a host metal }\end{array}$ & $\approx 2$ & 150 & RT & 1 & $\begin{array}{l}\text { Hydrogen (atomic } \mathrm{H} \text { ) intercallation in host } \\
\text { metals, metallic hydrides working at RT } \\
\text { are fully reversible. }\end{array}$ \\
\hline Complex compounds & $<18$ & 150 & $>100$ & 1 & $\begin{array}{l}\text { Complex compounds }\left(\left[\mathrm{AlH}_{4}\right]^{-} \text {or }\left[\mathrm{BH}_{4}\right]^{-}\right) \text {, } \\
\text { desorption at elevated temperature, adsorption } \\
\text { at high pressures. }\end{array}$ \\
\hline $\begin{array}{l}\text { Metals and complexes together } \\
\text { with water }\end{array}$ & $<40$ & $>150$ & RT & 1 & $\begin{array}{l}\text { Chemical oxidation of metals with water } \\
\text { and liberation of hydrogen, not directly } \\
\text { reversible? }\end{array}$ \\
\hline
\end{tabular}

The gravimetric density $\rho_{\mathrm{m}}$, the volumetric density $\rho_{\mathrm{v}}$, the working temperature $T$ and pressure $p$ are listed. RT stands for room temperature (25 $\left.{ }^{\circ} \mathrm{C}\right)$ 
thickness of a cylinder capped with two hemispheres is given by the following equation:

$$
\frac{d_{\mathrm{w}}}{d_{\mathrm{o}}}=\frac{\Delta p}{2 \cdot \sigma_{v}+\Delta p}
$$

where $d_{\mathrm{w}}$ is the wall thickness, $d_{\mathrm{o}}$ the outer diameter of the cylinder, $\Delta p$ the overpressure and $\sigma_{\mathrm{v}}$ the tensile strength of the material. The tensile strength of materials varies from $50 \mathrm{MPa}$ for aluminum to more than 1,100 $\mathrm{MPa}$ for high quality steel. Future, developments of new composite materials have a potential to increase the tensile strength above that of steel with a materials density which is less than half of the density of steel. Figure 4 shows the volumetric density of hydrogen inside the cylinder and the ratio of the wall thickness to the outer diameter of the pressure cylinder for stainless steel with a tensile strength of $460 \mathrm{MPa}$. The volumetric density of hydrogen increases with pressure and reaches a maximum, depending on the tensile strength of the material, above $100 \mathrm{MPa}$. However, the gravimetric density decreases with increasing pressure and the maximum gravimetric density is found for zero overpressure! Therefore, the increase in volumetric storage density is sacrificed by the reduction of the gravimetric density in pressurized gas systems.

The safety of pressurized cylinders is an issue of concern especially in highly populated regions. However, future pressure vessels are envisaged to consist of three layers: an inner polymer liner, over wrapped with a carbon-fiber composite (which is the stress-bearing component) and an outer layer of an aramid-material capable to withstand mechanical and corrosion damage. The target that the global industry has set for itself is a $70 \mathrm{MPa}$ cylinder with a mass of $110 \mathrm{~kg}$ resulting in a gravimetric storage density of 6 mass $\%$ and a volumetric storage density of $30 \mathrm{~kg} \mathrm{~m}^{-3}$ (Irani 2002).

Hydrogen can be compressed using standard piston-type mechanical compressors. Slight modifications of the seals in order to compensate for the higher diffusivity of

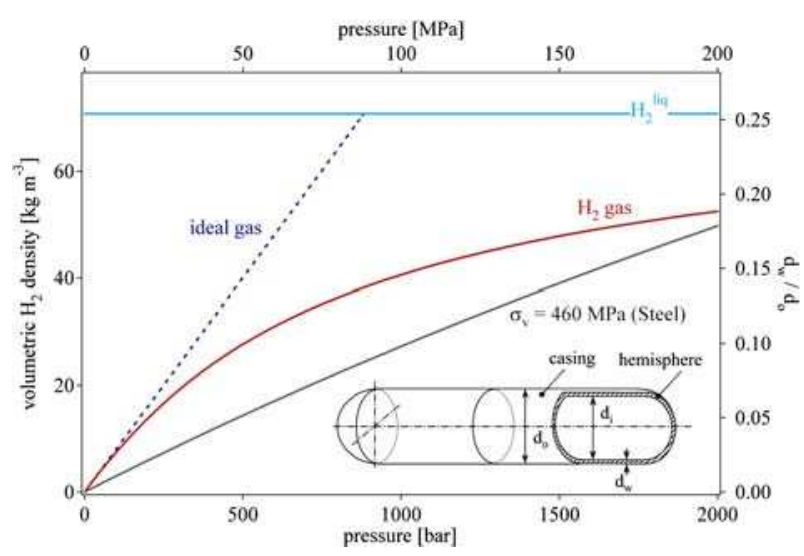

Fig. 4 Volumetric density of compressed hydrogen gas as a function of gas pressure including the ideal gas and liquid hydrogen. The ratio of the wall thickness to the outer diameter of the pressure cylinder is shown on the right-hand side for steel wit a tensile strength of $460 \mathrm{MPa}$. A schematic drawing of the pressure cylinder is shown as an inset 
hydrogen are sometimes necessary. The theoretical work necessary for the isothermal compression of hydrogen is given by the following equation:

$$
\Delta G=R \cdot T \cdot \ln \left(\frac{p}{p_{0}}\right)
$$

where $R$ stands for the gas constant $\left(R=8.314 \mathrm{~J} \mathrm{~mol}^{-1} \mathrm{~K}^{-1}\right), T$ for the absolute temperature and $p$ and $p_{0}$ for the end pressure and the starting pressure, respectively. The error of the work calculated with Eq. 3 in the pressure range of 0.1$100 \mathrm{MPa}$ is less than $6 \%$. The isothermal compression of hydrogen from 0.1 to $80 \mathrm{MPa}$ consumes therefore $2.21 \mathrm{kWh} \mathrm{kg}^{-1}$. In a real process the work consumption for compression is significantly higher because the compression is not isothermal. Metal hydrides can be used to compress hydrogen from a heat source only. Compression ratios of grater than 20:1 are possible with final pressures of more than $10 \mathrm{MPa}$ (Huston 1984).

The relatively low hydrogen density together with the very high gas pressures, diffusion problems and the cyclic stability in the systems are important drawbacks of the technically simple and on the laboratory scale well established high pressure storage method.

\subsection{Liquid hydrogen}

Liquid hydrogen is stored in cryogenic tanks at $21.2 \mathrm{~K}$ at ambient pressure. Due to the low critical temperature of hydrogen $(33 \mathrm{~K})$ liquid hydrogen can only be stored in open systems, because there is no liquid phase existent above the critical temperature. The pressure in a closed storage system at room temperature could increase to about $10^{4}$ bar. The volumetric density of liquid hydrogen is $70.8 \mathrm{~kg} \mathrm{~m}^{-3}$ and slightly higher than that of solid hydrogen $\left(70.6 \mathrm{~kg} \mathrm{~m}^{-3}\right)$. The challenges of the liquid hydrogen storage are the energy efficient liquefaction process and the thermal insulation of the cryogenic storage vessel in order to reduce the boil-off of hydrogen.

Normal hydrogen at room temperature contains $25 \%$ of the para form and $75 \%$ of the ortho form, according to the nuclear spin. The ortho form cannot be prepared in the pure state. Since the two forms differ in energy, the physical properties also differ. The melting and boiling points of para hydrogen are about $0.1 \mathrm{~K}$ lower than those of normal hydrogen. At $0 \mathrm{~K}$, all the molecules must be in a rotational ground state i.e. in the para form.

When hydrogen is cooled from room temperature (RT) to the normal boiling point $(\mathrm{nbp}=21.2 \mathrm{~K})$ the ortho hydrogen converts from an equilibrium concentration of $75 \%$ at RT to $50 \%$ at $77 \mathrm{~K}$ and $0.2 \%$ at nbp. The self conversion rate is an activated process and very slow, the half-life time of the conversion is greater than 1 year at $77 \mathrm{~K}$. The conversion reaction from ortho- to para-hydrogen is exothermic and the heat of conversion is also temperature dependent. At $300 \mathrm{~K}$ the heat of conversion is $270 \mathrm{~kJ} \mathrm{~kg}^{-1}$ and increases as the temperature decreases, where it reaches $519 \mathrm{~kJ} \mathrm{~kg}^{-1}$ at $77 \mathrm{~K}$. At lower temperatures than $77 \mathrm{~K}$ the enthalpy of conversion is $523 \mathrm{~kJ} \mathrm{~kg}^{-1}$ and almost constant. The enthalpy of conversion is greater than the latent heat of vaporization $\left(H_{\mathrm{V}}=451.9 \mathrm{~kJ} \mathrm{~kg}^{-1}\right)$ of normal and para hydrogen at the nbp. If the unconverted normal hydrogen is placed in a storage vessel, the enthalpy of conversion will be released in the vessel, which leads to the evaporation of the liquid hydrogen. The transformation from ortho- to 
para-hydrogen can be catalyzed by a number of surface active and paramagnetic species, e.g. normal hydrogen can be adsorbed on charcoal cooled with liquid hydrogen and desorbed in the equilibrium mixture. The conversion may take only a few minutes if a highly active form of charcoal is used. Other suitable ortho-para catalysts are metal such as tungsten or nickel, any paramagnetic oxides like chromium or gadolinium oxides. The nuclear spin is reversed without breaking the $\mathrm{H}-\mathrm{H}$ bond.

The simplest liquefaction cycle is the Joule-Thompson cycle (Linde cycle). The gas is first compressed, then cooled in a heat exchanger, before it passes through a throttle valve where it undergoes an isenthalpic Joule-Thompson expansion, producing some liquid. The cooled gas is separated from the liquid and returned to the compressor via the heat exchanger (Flynn 1992). The Joule-Thompson cycle works for gases, such as nitrogen, with a inversion temperature above room temperature. Hydrogen, however, warms upon expansion at room temperature. In order for hydrogen to cool upon expansion, its temperature must be below its inversion temperature of $202 \mathrm{~K}$. Therefore, hydrogen is usually pre-cooled using liquid nitrogen $(78 \mathrm{~K})$ before the first expansion step occurs. The free enthalpy change between gaseous hydrogen at $300 \mathrm{~K}$ and liquid hydrogen at $20 \mathrm{~K}$ is $1,1640 \mathrm{~kJ} \mathrm{~kg}^{-1}$ (Chen and Anghaie 1992). The theoretical energy (work) needed to liquefy hydrogen from RT is $W$ th $=3.23 \mathrm{kWh} \mathrm{kg}^{-1}$, the technical work is about $15.2 \mathrm{kWh} \mathrm{kg}^{-1}$ (von Ardenne et al. 1990) roughly one third of the higher heating value of the hydrogen combustion.

The boil-off rate of hydrogen from a liquid hydrogen storage vessel due to heat leak is a function of the size, the shape and the thermal insulation of the vessel. Theoretically the best shape is a sphere since it has the least surface to volume ratio and stress and strain are distributed uniformly. However, large size, spherical containers are expensive because of their manufacturing difficulty. Since boil-off losses due to heat leak is proportional to the surface to volume ratio, the evaporation rate diminishes drastically as the storage tank size increases. For double-walled vacuuminsulated spherical dewars, boil-off losses are typically $0.4 \%$ per day for tanks having a storage volume of $50 \mathrm{~m}^{3}, 0.2 \%$ for $100 \mathrm{~m}^{3}$ tanks, and $0.06 \%$ for $20,000 \mathrm{~m}^{3}$ tanks (Abe et al. 1998). The boil-off hydrogen can be oxidized with air on a catalyst like Pd (cold combustion) or used in a fuel cell to produce electricity.

The relatively large amount of energy necessary for the liquefaction and the continuous boil-off of hydrogen limit the possible applications for liquid hydrogen storage systems. Applications where the cost of hydrogen is not an important issue and the hydrogen is consumed in a rather short time, e.g. air and space, are possible.

\subsection{Physisorption of hydrogen}

The adsorption of a gas on a surface is a consequence of the field force at the surface of the solid, called the adsorbent, which attracts the molecules of the gas or vapor, called adsorbate. The origin of the physisorption of gas molecules on the surface of a solid are resonant fluctuations of the charge distributions and are therefore called dispersive interactions or Van der Waals interactions. In the physisorption process a gas molecule interacts with several atoms at the surface of the solid. The interaction is composed of an attractive term which diminishes with the distance between the molecule and the surface to the power of -6 and a repulsive term which diminishes with the distance to the power of -12 . Therefore, the potential energy of molecule 
shows a minimum at a distance of approximately one molecular radius of the adsorbate and the energy minimum is of the order of $0.01-0.1 \mathrm{eV}\left(1-10 \mathrm{~kJ} \mathrm{~mol}^{-1}\right)$ (London 1930). Due to the weak interaction significant physisorption is only observed at low temperatures $(<273 \mathrm{~K})$. Once a monolayer of adsorbate molecules is formed the gaseous molecule interact with a surface of the liquid or solid adsorbate. Therefore, the binding energy of the second layer of adsorbate molecules is similar to the latent heat of sublimation or vaporization of the adsorbate. Consequently, the adsorption at a temperature equal or greater to the boiling point of the adsorbate at a given pressure leads to the adsorption of one single monolayer (Brunauer et al. 1938). In order to estimate the quantity of adsorbate in the monolayer the density of the liquid adsorbate and the volume of the molecule can be used. If a liquid is assumed to consist of a closed packed fcc structure, the minimum surface area $S_{\mathrm{ml}}$ for $1 \mathrm{~mol}$ of adsorbate in a monolayer on a substrate can be calculated from the density of the liquid $\rho_{\text {liq }}$ and the molecular mass of the adsorbate $M_{\text {ads }}$.

$$
S_{\mathrm{ml}}=\frac{\sqrt{3}}{2} \cdot\left(\sqrt{2 \cdot N_{\mathrm{A}}} \cdot \frac{M_{\mathrm{ads}}}{\rho_{\text {liq }}}\right)^{\frac{2}{3}}
$$

$N_{\mathrm{A}}$ stands for the Avogadro constant $\left(N_{\mathrm{A}}=6.022 \times 10^{23} \mathrm{~mol}^{-1}\right)$. The monolayer surface area for hydrogen is $S_{\mathrm{ml}}\left(\mathrm{H}_{2}\right)=85,917 \mathrm{~m}^{2} \mathrm{~mol}^{-1}$. The amount of adsorbate $m_{\text {ads }}$ on a substrate material with a specific surface area $S_{\text {spec }}$ is then given by $m_{\text {ads }}=$ $M_{\mathrm{ads}} S_{\mathrm{sped}} / S_{\mathrm{ml}}$. In the case of carbon as the substrate and hydrogen as the adsorbate, the maximum specific surface area of carbon is $S_{\text {spec }}=1,315 \mathrm{~m}^{2} \mathrm{~g}^{-1}$ (single side graphene sheet) and the maximum amount of adsorbed hydrogen is $m_{\mathrm{ads}}=3.0$ mass $\%$. From this theoretical approximation we may conclude that the amount of adsorbed hydrogen is proportional to the specific surface area of the adsorbent with $m_{\text {ads }} / S_{\text {spec }}=2.27 \times 10^{-3}$ mass $\% \mathrm{~m}^{-2} \mathrm{~g}$ and can only be observed at very low temperatures.

Much work on reversible hydrogen sorption by carbon nanostructures was stimulated by the findings published in an article from Dillon et al. (1997). This paper describes the results of a brief hydrogen desorption experiment. The authors estimated the hydrogen storage capacity of carbon nanotubes at that time to be 5-10 mass\%. The investigation was carried out on a carbon sample containing an estimated (TEM micrographs) amount of 0.1-0.2 mass $\%$ of single wall carbon nanotubes. The amount of hydrogen desorbed in the high-temperature peak, which is roughly 5-10 times smaller than the low temperature physisorption peak, was 0.01 mass \%. The authors concluded 'Thus the gravimetric storage density per SWNT ranges from 5 to 10 mass\%'. Three years later in a report to the DOE (2000) this peak has moved significantly by $300 \mathrm{~K}$ up to $600 \mathrm{~K}$. Apparently the reported results are inconsistent. Hirscher et al. (2001) clarified the situation and showed that the desorption of hydrogen originates from Ti-alloy particle, introduced during the ultrasonic treatment, in the sample rather than from the carbon nanotubes.

The main difference between carbon nanotubes and high surface area graphite is the curvature of the graphene sheets and the cavity inside the tube. In microporous solids with capillaries which have a width not exceeding a few molecular diameters, the potential fields from opposite walls will overlap so that the attractive force acting on adsorbate molecules will be increased as compared with that on a flat carbon 
surface (Gregg and Sing 1967). This phenomenon is the main motivation for the investigation of the hydrogen interaction with carbon nanotubes.

The investigation of the absorption of the hydrogen inside the tubes has shown that it is energetically more favorable for the hydrogen atoms to recombine and form molecules, which are then physisorbed inside the nanotube. Ma et al. (2001) performed a molecular dynamics simulation for $\mathrm{H}$ implantation. The hydrogen atoms $(20 \mathrm{eV})$ were implanted through the side walls of a single wall carbon nanotube (5.5) consisting of 150 atoms and having a diameter of $0.683 \mathrm{~nm}$. They found that the hydrogen atoms recombine to molecules inside the tube and arrange themselves to a concentric tube. The hydrogen pressure inside the SWNT increases as the number of injected atoms increases and reaches $35 \mathrm{GPa}$ for 90 atoms (5 mass \%). This simulation does not exhibit a condensation of hydrogen inside the nanotube. The critical temperature of hydrogen $\left(\mathrm{H}_{2}\right)$ is $33.25 \mathrm{~K}$ (Leung et al. 1976). Therefore, at temperatures above $33.25 \mathrm{~K}$ and at all pressures hydrogen does not exist as a liquid phase, hydrogen is either a gas or a solid. The density of liquid and solid hydrogen at the melting point $\left(T_{\mathrm{m}}=14.1 \mathrm{~K}\right)$ is $70.8 \mathrm{~kg} \mathrm{~m}^{-3}$ and $70.6 \mathrm{~kg} \mathrm{~m}^{-3}$, respectively. Measurement of the latent heat of condensation of nitrogen on carbon black (Beebe et al. 1947) showed, that the heat for the adsorption of one monolayer is between 11 and $12 \mathrm{~kJ} \mathrm{~mol}^{-1}(0.11-0.12 \mathrm{eV})$ and drops for subsequent layers to the latent heat of condensation for nitrogen which is $5.56 \mathrm{~kJ} \mathrm{~mol}^{-1}(0.058 \mathrm{eV})$. If we assume, that hydrogen behaves similar to nitrogen, hydrogen would only form one monolayer of liquid at the surface of carbon at temperatures above the boiling point. Geometrical considerations of the nanotubes lead to the specific surface area and therefore, to the maximum amount of condensed hydrogen in a surface monolayer. Figure 5 shows the maximum amount of hydrogen in mass \% for the physisorption of hydrogen on carbon nanotubes (Züttel et al. 2002). The maximum amount of adsorbed hydrogen is 3.0 mass \% for single wall carbon nanotubes (SWNT) with a specific surface area of $1,315 \mathrm{~m}^{2} \mathrm{~g}^{-1}$ at a temperature of $77 \mathrm{~K}$.

From adsorption-desorption experiments it is evident that reversible physisorption exclusively takes place with all samples. The amount of adsorbed hydrogen

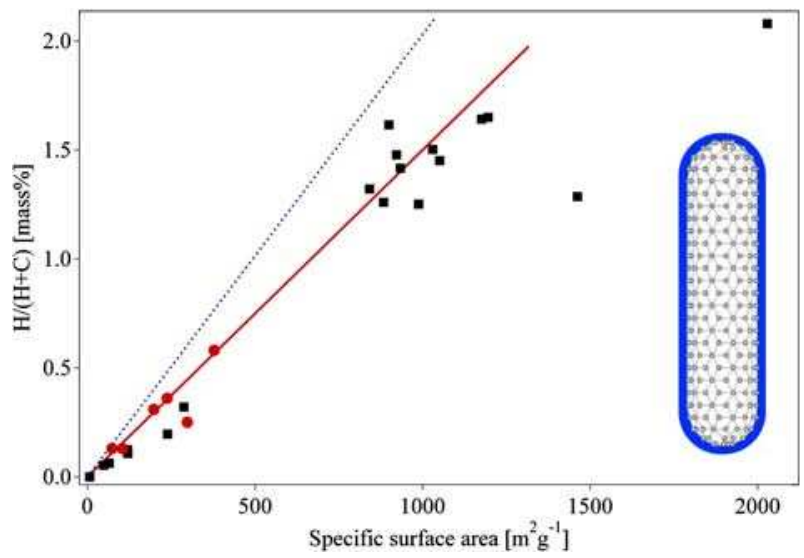

Fig. 5 Reversible amount of hydrogen (electrochemical measurement at $298 \mathrm{~K}$ ) versus the BET surface area (round markers) of a few carbon nanotube samples including two measurements on high surface area graphite (HSAG) samples together with the fitted line. Hydrogen gas adsorption measurements at $77 \mathrm{~K}$ from Nijkamp et al. (2001) (square markers) are included. The dotted line represents the calculated amount of hydrogen in a monolayer at the surface of the substrate 
correlates well with the specific surface area of the sample (Nijkamp et al. 2001) (Fig. 5). A few papers on electrochemical measurements at room temperature of the hydrogen uptake and release have been published (Nützenadel et al. 1999, 2001; Züttel et al. 2001; Lee et al. 2000). The electrochemical hydrogen absorption is reversible. The maximum discharge capacity measured at $298 \mathrm{~K}$ is 2 mass \% with a very small discharge current (discharge process for 1,000 h). The few round markers together with the fitted line in Fig. 3 are electrochemical results. It is remarkable, that the measurements of the hydrogen uptake in the gas phase at $77 \mathrm{~K}$ exhibit the same quantities as the electrochemical measurements at room temperature $298 \mathrm{~K}$. In the electrochemical charge process hydrogen atoms are left back at the surface of the electrode when the electron transfer from the conductor to the water molecules takes place. The hydrogen atoms recombine to hydrogen molecules. This process goes on until the surface is completely covered with a monolayer of physisorbed $\mathrm{H}_{2}$ molecules. Any further hydrogen does not interact with the attractive Van der Waals forces of the surface. The hydrogen molecules become very mobile and form gas bubbles, which are released from the electrode surface. The formation of a stable monolayer of hydrogen at the electrode surface at room temperature is only possible if either the hydrogen atoms or the hydrogen molecules are immobile, i.e. their surface diffusion has to be cinematically hindered by a large energy barrier probably due to the adsorbed electrolyte $\left(\mathrm{H}_{2} \mathrm{O}\right)$ molecules in the second layer. An other possible reaction path was first reported (Lee et al. 2001) as a result of densityfunctional calculation. The result of the calculation is that hydrogen atoms tend to chemisorb at the exterior surface of a nanotube. The atoms can then flip in and finally at high coverage recombine to hydrogen molecules forming a concentric cylinder in the cavity of the nanotube. If the binding energy of the chemisorbed hydrogen is relatively low as compared to the energy in hydrocarbons, the absorbed amount of hydrogen is proportional to the surface area of the carbon sample and could also desorb at rather positive electrochemical potential.

In conclusion: the reversible hydrogen sorption process is based on the physisorption. The amount of adsorbed hydrogen is proportional to the BET surface area of the nanostructured carbon sample. The amount of hydrogen adsorbed from the gas phase at $77 \mathrm{~K}$ and electrochemically at room temperature is $1.5 \times 10^{-}$ ${ }^{3}$ mass $\% \mathrm{~m}^{-2} \mathrm{~g}$. Together with the maximum specific surface area of carbon $\left(1,315 \mathrm{~m}^{2} \mathrm{~g}^{-1}\right)$ the maximum absorption capacity of carbon nanostructures is 2 mass \%. The experimental results are in good agreement with the theoretical estimations if we take into account that the measurements were carried out at a temperature of $77 \mathrm{~K}$ which is still far above the critical temperature of hydrogen of $32 \mathrm{~K}$ and therefore the monolayer of hydrogen is not complete at $77 \mathrm{~K}$. No evidence for an influence of the geometric structure of the nanostructured carbon on the amount of hydrogen absorbed was found. It is quite obvious, that the curvature of nanotubes may only influence the adsorption energy but not the amount of adsorbed hydrogen. Furthermore, all attempts to open the nanotubes and absorb hydrogen inside the tubes did not show an increased absorption of hydrogen molecules.

The big advantage of the physisorption for hydrogen storage are the low operating pressure, the relatively low cost of the materials involved and the simple design of the storage system. The rather small amount of hydrogen adsorbed on carbon together with the low temperatures necessary are significant drawbacks of the hydrogen storage based on physisorption. 

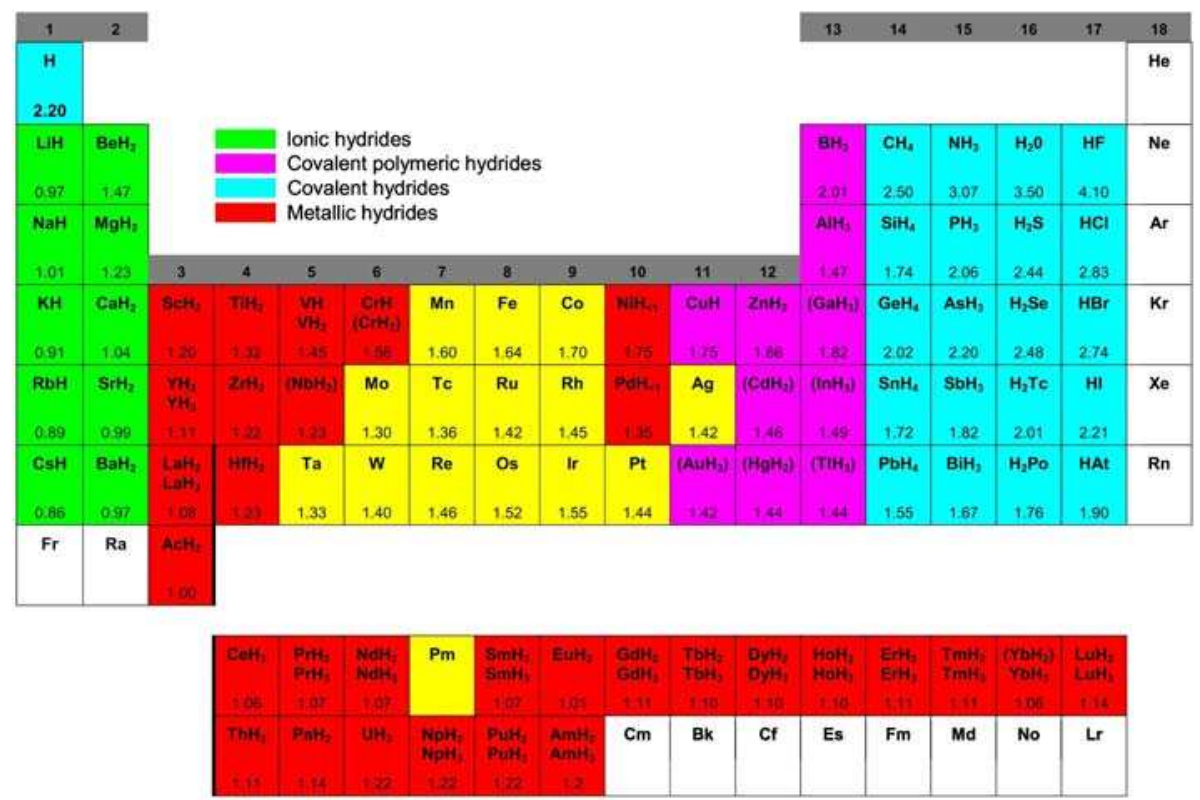

Fig. 6 Table of the binary hydrides and the Allred-Rochow electronegativity (Huheey 1983). Most elements react with hydrogen to form ionic, covalent or metallic binary hydrides

\subsection{Metalhydrides}

Metals, intermetallic compounds and alloys in general react with hydrogen and form mainly solid metal-hydrogen compounds. Hydrides exist as ionic, polymeric covalent, volatile covalent and metallic hydrides (Fig. 6). The demarcation between the various types of hydrides is not sharp, they merge into each other according to the electronegativities of the elements concerned. This chapter focuses on metallic hydrides, i.e. metals and intermetallic compounds, which form together with hydrogen metallic hydrides. Hydrogen reacts at elevated temperature with many transition metals and their alloys to form hydrides. The electropositive elements are the most reactive, i.e. scandium, yttrium, the lanthanides, the actinides, and the members of the titanium and vanadium groups. The binary hydrides of the transition metals are predominantly metallic in character and are usually referred to as metallic hydrides. They are good conductors of electricity, possess a metallic or graphite-like appearance, and can often be wetted by mercury. Many of these compounds $\left(\mathrm{MH}_{n}\right)$ show large deviations from ideal stoichiometry $(n=1,2,3)$ and can exist as multi-phase systems. The lattice structure is that of a typical metal with atoms of hydrogen on the interstitial sites; for this reason they are also called interstitial hydrides. This type of structure has the limiting compositions $\mathrm{MH}, \mathrm{MH}_{2}$, and $\mathrm{MH}_{3}$; the hydrogen atoms fit into octahedral or tetrahedral holes in the metal lattice, or a combination of the two types. The hydrogen carries a partial negative charge, depending on the metal an exception is, for example, $\mathrm{PdH}_{0.7}$ (Pearson 1985). Only a small number of the transition metals are without known stable hydrides. A considerable 'hydride gap' exists in the periodic table, beginning at group $6(\mathrm{Cr})$ up to group $11(\mathrm{Cu})$, in which the only hydrides are palladium hydride $\left(\mathrm{PdH}_{0.7}\right)$, the very unstable nickel hydride 
$\left(\mathrm{NiH}_{<1}\right)$, and the poorly defined hydrides of chromium $\left(\mathrm{CrH}, \mathrm{CrH}_{2}\right)$ and copper $(\mathrm{CuH})$. In palladium hydride, the hydrogen has high mobility and probably a very low charge density. In the finely divided state, platinum and ruthenium are able to adsorb considerable quantities of hydrogen, which thereby becomes activated. These two elements, together with palladium and nickel, are extremely good hydrogenation catalysts, although they do not form hydrides (Müller et al. 1968). Especially interesting are the metallic hydrides of intermetallic compounds, in the simplest case the ternary system $\mathrm{AB}_{x} \mathrm{H}_{n}$, because the variation of the elements allows to tailor the properties of the hydrides. The A element is usually a rear earth or an alkaline earth metal and tends to form a stable hydride. The B element is often a transition metal and forms only unstable hydrides. Some well defined ratios of B to A in the intermetallic compound $x=0.5,1,2,5$ have been found to form hydrides with a hydrogen to metal ratio of up to two.

The reaction of hydrogen gas with a metal is called the absorption process and can be described in terms of a simplified one-dimensional potential energy curve (onedimensional Lennard-Jones potential, Fig. 7) (Lennard-Jones 1932). Far from the metal surface the potential of a hydrogen molecule and of 2 hydrogen atoms are separated by the dissociation energy $\left(\mathrm{H}_{2} \rightarrow 2 \mathrm{H}, E_{\mathrm{D}}=435.99 \mathrm{~kJ} \mathrm{~mol}^{-1}\right)$. The first attractive interaction of the hydrogen molecule approaching the metal surface is the Van der Waals force leading to the physisorbed state $\left(E_{\mathrm{Phys}} \approx 10 \mathrm{~kJ} \mathrm{~mol}^{-1}\right)$ approximately one hydrogen molecule radius $(\approx 0.2 \mathrm{~nm})$ from the metal surface. Closer to the surface the hydrogen has to overcome an activation barrier for dissociation and formation of the hydrogen metal bond. The height of the activation barrier depends on the surface elements involved. Hydrogen atoms sharing their electron with the metal atoms at the surface are then in the chemisorbed state

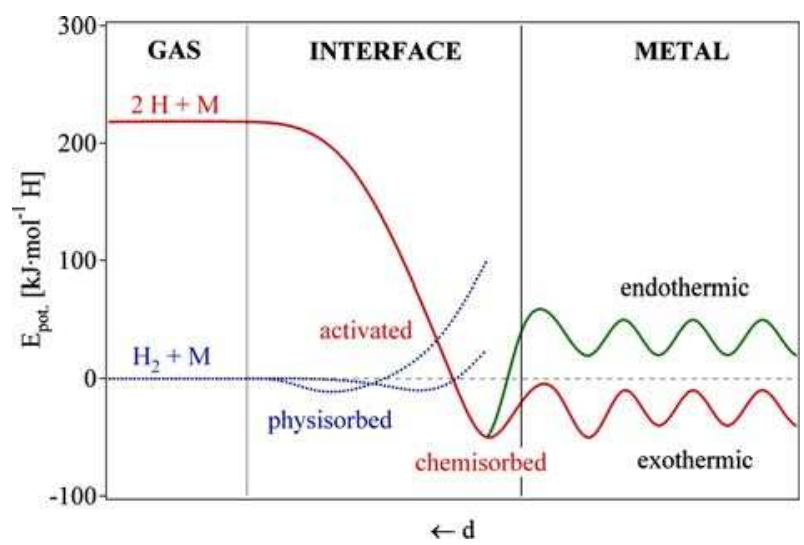

Fig. 7 One-dimensional potential energy curve (one-dimensional Lennard-Jones potential for a hydrogen metal system (Müller et al. 1968)). Far from the metal surface the potential of a hydrogen molecule and of 2 hydrogen atoms are separated by the dissociation energy. The first attractive interaction of the hydrogen molecule approaching the metal surface is the Van der Waals force leading to the physisorbed state. Closer to the surface the hydrogen has to overcome an activation barrier for dissociation and formation of the hydrogen metal bond. Hydrogen atoms sharing their electron with the metal atoms at the surface are in the chemisorbed state. In the next step the chemisorbed hydrogen atom can jump in the subsurface layer and finally diffuse on the interstitial sites through the host metal lattice. The hydrogen atoms contribute with their electron to the band structure of the metal 
$\left(E_{\mathrm{Chem}} \approx 50 \mathrm{~kJ} \mathrm{~mol}^{-1} \mathrm{H}_{2}\right.$ ). The chemisorbed hydrogen atoms may have a high surface mobility, interact with each other and form surface phases at sufficiently high coverage. In the next step the chemisorbed hydrogen atom can jump in the subsurface layer and finally diffuse on the interstitial sites through the host metal lattice. The hydrogen atoms contribute with their electron to the band structure of the metal. The hydrogen is at small hydrogen to metal ratio $(\mathrm{H} / \mathrm{M}<0.1)$ exothermically dissolved (solid-solution, $\alpha$-phase) in the metal (Fig. 8). The metal lattice expands proportional to the hydrogen concentration by approximately $2-3 \AA^{3}$ per hydrogen atom (Fukai 1989). At greater hydrogen concentrations in the host metal (H/M > 0.1 ) a strong $\mathrm{H}-\mathrm{H}$ interaction due to the lattice expansion becomes important and the hydride phase ( $\beta$-phase) nucleates and grows. The hydrogen concentration in the hydride phase is often found to be $\mathrm{H} / \mathrm{M}=1$. The volume expansion between the coexisting $\alpha$ - and the $\beta$-phase corresponds in many cases $10-20 \%$ of the metal lattice. Therefore, at the phase boundary large stress is built up and often leads to a decrepitation of brittle host metals such as intermetallic compounds. The final hydride is a powder with a typical particle size of $10-100 \mu \mathrm{m}$.

The thermodynamic aspects of the hydride formation from gaseous hydrogen is described by means of pressure-composition isotherms (Fig. 9). While the solid solution and hydride phase coexists, the isotherms show a flat plateau, the length of which determines the amount of $\mathrm{H}_{2}$ stored. In the pure $\beta$-phase, the $\mathrm{H}_{2}$ pressure rises

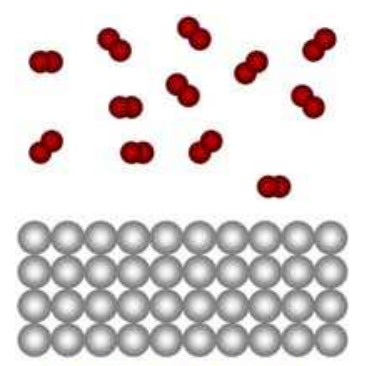

Hydrogen \& metal

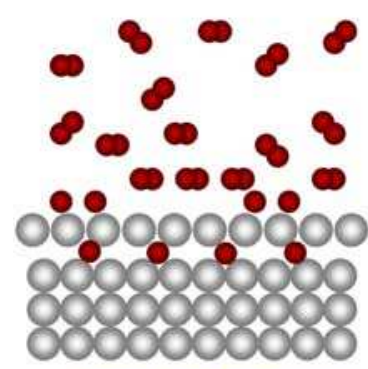

Subsurface hydrogen

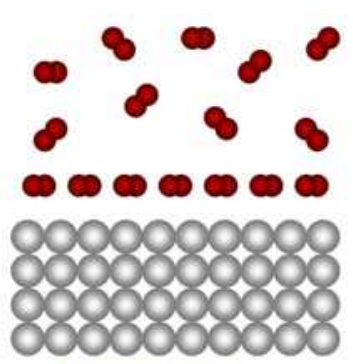

Physisorption

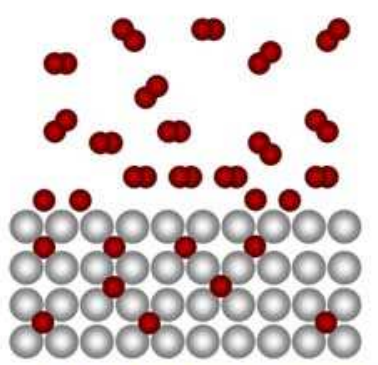

Solid solution ( $\alpha$-phase)

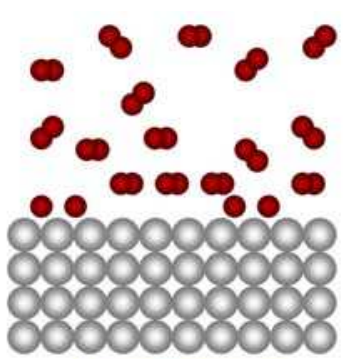

Chemisorption

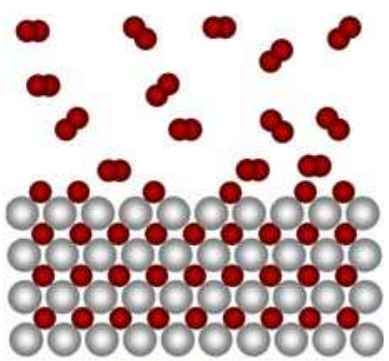

Hydride ( $\beta$-phase)

Fig. 8 The six distinct states of hydrogen absorption in metals. On the upper left-hand side the metal and hydrogen gas are in two separate phases. Hydrogen molecules can be found in the physisorbed state at low temperature. Hydrogen molecules interact with the electrons at the metal surface, dissociate and bind to the metal atoms at the surface and form the chemisorbed state. Hydrogen can the jump in a subsurface layer and diffuse into the metal host lattice as a solid solution ( $\alpha$-phase). Finally, the hydrogen-hydrogen interaction (volume expansion) becomes important and the hydride phase ( $\beta$-phase) is formed

Springer 


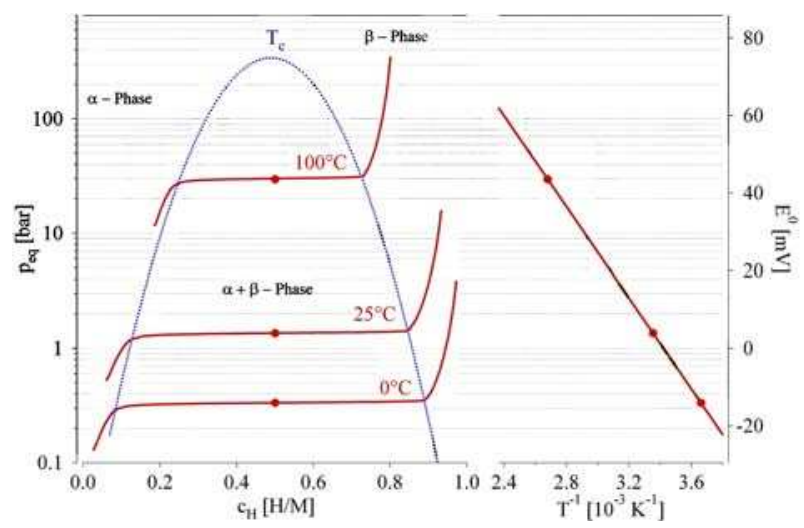

Fig. 9 Pressure composition isotherms for the hydrogen absorption in a typical intermetallic compound on the left-hand side. The solid solution ( $\alpha$-phase), the hydride phase ( $\beta$-phase) and the region of the coexistence of the two phases. The coexistange region is characterized by the flat plateau and ends at the critical temperature $T_{\mathrm{c}}$. The construction of the Van't Hoff plot is shown on the right-hand side. The slope of the line is equal to the enthalpy of formation divided by the gas constant and the interception is equal to the entropy of formation divided by the gas constant

steeply with the concentration. The two-phase region ends in a critical point $T_{\mathrm{c}}$, above which the transition from $\alpha$ - to $\beta$-phase is continuous. The equilibrium pressure $p_{\text {eq }}$ as a function of temperature is related to the changes $\Delta H$ and $\Delta S$ of enthalpy and entropy, respectively, by the Van't Hoff equation:

$$
\ln \left(\frac{p_{\mathrm{eq}}}{p_{\mathrm{eq}}^{0}}\right)=\frac{\Delta H}{R} \cdot \frac{1}{T}-\frac{\Delta S}{R}
$$

As the entropy change corresponds mostly to the change from molecular hydrogen gas to dissolved solid hydrogen, it amounts approximately to the standard entropy of hydrogen $\left(S^{0}=130 \mathrm{~J} \mathrm{~K}^{-1} \mathrm{~mol}^{-1}\right)$ and is therefore, $\Delta S_{\mathrm{f}} \approx-130 \mathrm{~J} \mathrm{~K}^{-1} \mathrm{~mol}^{-1}$ $\mathrm{H}_{2}$ for all metal-hydrogen systems. The enthalpy term characterizes the stability of the metal hydrogen bond. To reach an equilibrium pressure of 1 bar at $300 \mathrm{~K} \Delta H$ should amount to $19.6 \mathrm{~kJ} \mathrm{~mol}^{-1} \mathrm{H}$. The stability of metal hydrides is usually presented in the form of Van't Hoff plots according to Eq. 6 (Fig. 10). The most stable binary hydrides have enthalpies of formation of $\Delta H_{\mathrm{f}}=-226 \mathrm{~kJ} \mathrm{~mol}^{-1} \mathrm{H}_{2}$ e.g. $\mathrm{HoH}_{2}$. The least stable hydrides are $\mathrm{FeH}_{0.5}, \mathrm{NiH}_{0.5}$ and $\mathrm{MoH}_{0.5}$ with enthalpies of formation of $\Delta H_{\mathrm{f}}=+20 \mathrm{~kJ} \mathrm{~mol}^{-1} \mathrm{H}_{2}, \Delta H_{\mathrm{f}}=+20 \mathrm{~kJ} \mathrm{~mol}^{-1} \mathrm{H}_{2}$, and $\Delta H_{\mathrm{f}}=+92 \mathrm{~kJ} \mathrm{~mol}^{-1} \mathrm{H}_{2}$, respectively (Griessen and Riesterer 1988).

Metal hydrides have due to the phase transition upon hydrogen absorption the very appreciated property of absorbing large amounts of hydrogen at a constant pressure, i.e. the pressure does not increase with the amount of hydrogen absorbed as long as the phase transition takes place. The characteristics of the hydrogen absorption and desorption can be tailored by partial substitution of the constituent elements in the host lattice. Some metal hydrides absorb and desorb hydrogen at ambient temperature and close to atmospheric pressure. Several families of intermetallic compounds listed in Table 2 are interesting for hydrogen storage. They all consist of an element with a high affinity to hydrogen, the A-element, and an 


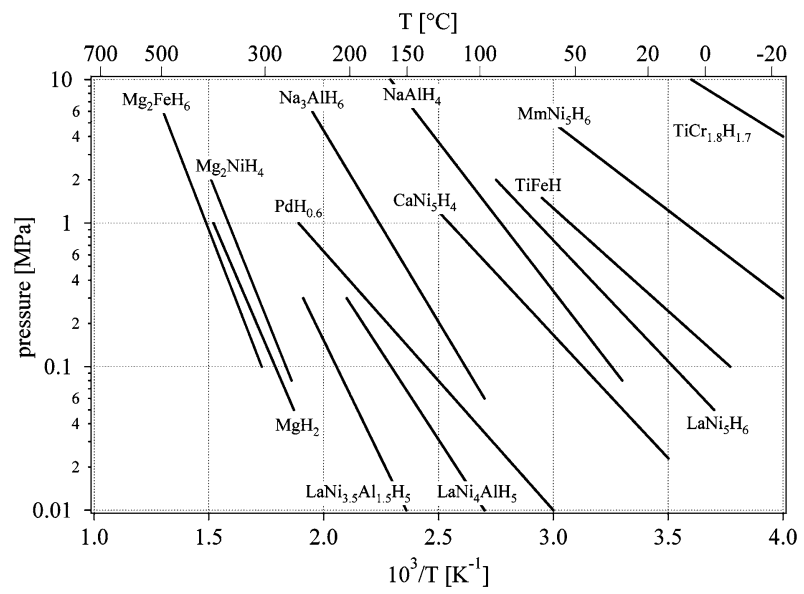

Fig. 10 Van't Hoff plots of some selected hydrides. The stabilization of the hydride of $\mathrm{LaNi}_{5}$ by the partial substitution of nickel with aluminum in $\mathrm{LaNi}_{5}$ is shown as well as the substitution of lanthanum with mischmetal (e.g. $51 \% \mathrm{La}, 33 \% \mathrm{Ce}, 12 \% \mathrm{Nd}, 4 \% \mathrm{Pr}$ )

Table 2 The most important families of hydride forming intermetallic compounds including the prototype and the structure

\begin{tabular}{llll}
\hline Intermetallic compound & Prototype & Hydrides & Structure \\
\hline $\mathrm{AB}_{5}$ & $\mathrm{LaNi}_{5}$ & $\mathrm{LaNiH}_{6}$ & Haucke phases, hexagonal \\
$\mathrm{AB}_{2}$ & $\mathrm{ZrV}_{2}, \mathrm{ZrMn}_{2}, \mathrm{TiMn}_{2}$ & $\mathrm{ZrV}_{2} \mathrm{H}_{5.5}$ & Laves phase, hexagonal or cubic \\
$\mathrm{AB}_{3}$ & $\mathrm{CeNi}_{3}, \mathrm{YFe}_{3}$ & $\mathrm{CeNi}_{3} \mathrm{H}_{4}$ & Hexagonal, $\mathrm{PuNi}_{3}$-typ \\
$\mathrm{A}_{2} \mathrm{~B}_{7}$ & $\mathrm{Y}_{2} \mathrm{Ni}_{7}, \mathrm{Th}_{2} \mathrm{Fe}_{7}$ & $\mathrm{Y}_{2} \mathrm{Ni}_{7} \mathrm{H}_{3}$ & Hexagonal, $\mathrm{Ce}_{2} \mathrm{Ni}_{7}$-typ \\
$\mathrm{A}_{6} \mathrm{~B}_{23}$ & $\mathrm{Y}_{6} \mathrm{Fe}_{23}$ & $\mathrm{Ho}_{6} \mathrm{Fe}_{23} \mathrm{H}_{12}$ & Cubic, Th \\
$\mathrm{ABn}_{23}$-typ \\
$\mathrm{AB}$ & $\mathrm{TiFe}_{\mathrm{Z}} \mathrm{ZrNi}$ & $\mathrm{TiFeH}_{2}$ & Cubic, CsCl- or CrB-typ \\
$\mathrm{A}_{2} \mathrm{~B}$ & $\mathrm{Mg}_{2} \mathrm{Ni}, \mathrm{Ti}_{2} \mathrm{Ni}$ & $\mathrm{Mg}_{2} \mathrm{NiH}_{4}$ & Cubic, MoSi \\
\hline
\end{tabular}

$\mathrm{A}$ is an element with a high affinity to hydrogen, and $\mathrm{B}$ is an element with a low affinity to hydrogen

element with a low affinity to hydrogen, the B-element. The latter is often at least partially nickel, since nickel is an excellent catalyst for the hydrogen dissociation.

One of the most interesting features of the metallic hydrides is the extremely high volumetric density of the hydrogen atoms present in the host lattice. The highest volumetric hydrogen density know today is $150 \mathrm{~kg} \mathrm{~m}^{-3}$ found in $\mathrm{Mg}_{2} \mathrm{FeH}_{6}$ and $\mathrm{Al}\left(\mathrm{BH}_{4}\right)_{3}$. Both hydrides belong to the complex hydrides and will be discussed in the next chapter. Metallic hydrides reach a volumetric hydrogen density of $115 \mathrm{~kg} \mathrm{~m}^{-3}$ e.g. $\mathrm{LaNi}_{5}$. Most metallic hydrides absorb hydrogen up to a hydrogen to metal ratio of $\mathrm{H} / \mathrm{M}=2$. Greater ratios up to $\mathrm{H} / \mathrm{M}=4.5$ e.g. $\mathrm{BaReH}_{9}$, (Yvon 1998) have been found, however all hydrides with a hydrogen to metal ratio of more than 2 are ionic or covalent compounds and belong to the complex hydrides.

Metal hydrides are very effective to store large amounts of hydrogen in a safe and compact way. All the reversible hydrides working around ambient temperature and atmospheric pressure consist of transition metals and therefore the gravimetric hydrogen density is limited to less than 3 mass \%. To explore the properties of the light weight metal hydrides is still a challenge. 


\subsection{Complex hydrides}

The group one two and three light metals, e.g. $\mathrm{Li}, \mathrm{Mg}, \mathrm{B}, \mathrm{Al}$, build a large variety of metal-hydrogen complexes. They are especially interesting because of their light weight and the number of hydrogen atoms per metal atom which is in many cases 2 . The main difference of the complex hydrides to the above described metallic hydrides is the transition to an ionic or covalent compound of the metals upon hydrogen absorption. The hydrogen in the complex hydrides is often located in the corners of a tetraeder with boron or aluminum in the center. The negative charge of the anion, $\left[\mathrm{BH}_{4}\right]^{-}$and $\left[\mathrm{AlH}_{4}\right]^{-}$is compensated by a cation e.g. $\mathrm{Li}$ or $\mathrm{Na}$. The hydride complexes of borane, the tetrahydroborates $\mathrm{M}\left(\mathrm{BH}_{4}\right)$, and of alane the tetrahydroaluminate $\mathrm{M}\left(\mathrm{AlH}_{4}\right)$ are interesting storage materials, however, they were known to be stable and decompose only at elevated temperatures and often above the melting point of the complex.

Bogdanović and Swickardi (1997) presented in 1996 for the first time adsorption and desorption pressure-concentration isotherms of catalyzed $\mathrm{NaAlH}_{4}$ at temperature of 180 and $210^{\circ} \mathrm{C}$. The isotherms exhibit an absence of hysteresis and a nearly horizontal pressure plateau. Furthermore, the catalyzed system reversibly absorbed and desorbed hydrogen up to 4.2 mass $\%$ and the mechanism of the two step reaction was described. A more detailed study of the $\mathrm{NaAlH}_{4}$ with an improved catalyst was published in 2000 by Bogdanović et al. (2000). A desorption hydrogen pressure of 2 bar at $60^{\circ} \mathrm{C}$ was found and the enthalpy for the dissociation reaction was determined to be $37 \mathrm{~kJ} \mathrm{~mol}^{-1}$ and $47 \mathrm{~kJ} \mathrm{~mol}^{-1}$ for the first dissociation step of Ti-doped $\mathrm{NaAlH}_{4}: 3 \mathrm{NaAlH}_{4} \rightarrow \mathrm{Na}_{3} \mathrm{AlH}_{6}+2 \mathrm{Al}+3 \mathrm{H}_{2}(3.7 \mathrm{wt} \% \mathrm{H})$ and the second $\mathrm{Na}_{3} \mathrm{AlH}_{6} \rightarrow 3 \mathrm{NaH}+\mathrm{Al}+3 / 2 \mathrm{H}_{2}(3.0 \mathrm{wt} \% \mathrm{H})$, respectively. Therefore, the equilibrium hydrogen pressure at room temperature is approximately 1 bar. Furthermore, the reaction is reversible, a complete conversion to product was achieved at $270^{\circ} \mathrm{C}$ under 175 bar hydrogen pressure in 2-3 h (Dymova et al. 1974).

The first report of a pure alkali metal tetrahydroboride appeared in 1940 by Schlesinger and Brown (1940) who synthesized the lithiumtetrahydroboride (lithiumborohydride) $\left(\mathrm{LiBH}_{4}\right)$ by the reaction of ethyllithium with diborane $\left(\mathrm{B}_{2} \mathrm{H}_{6}\right)$. The direct reaction of the corresponding metal with diborane in etheral solvents under suitable conditions produces high yields of the tetrahydroborides (Schlesinger et al. 1953) $2 \mathrm{MH}+\mathrm{B}_{2} \mathrm{H}_{6} \rightarrow 2 \mathrm{MBH}_{4}$ where $\mathrm{M}=\mathrm{Li}, \mathrm{Na}, \mathrm{K}$ etc. Direct synthesis from the metal, boron and hydrogen at $550-700^{\circ} \mathrm{C}$ and $30-150$ bar $\mathrm{H}_{2}$ has been reported to yield the lithium salt, and it has been claimed that such a method is generally applicable to groups IA and IIA metals (Goerrig 1958). The reaction involving either the metal or the metal hydride, or the metal together with triethylborane in an inert hydrocarbon has formed the basis of a patent $\mathrm{M}+\mathrm{B}+2 \mathrm{H}_{2} \rightarrow \mathrm{MBH}_{4}$, where $\mathrm{M}=\mathrm{Li}, \mathrm{Na}$, K etc.

The stability of metal tetrahydroborides has been discussed in relation to their percentage ionic character, and those compounds with less ionic character than diborane are expected to be highly unstable (Schrauzer 1955). Steric effects have also been suggested to be important in some compounds (Lippard and Ucko 1968; Lipscomb 1963). The special feature exhibited by the covalent metal hydroborides is that the hydroboride group is bonded to the metal atom by bridging hydrogen atoms similar to the bonding in diborane, which may be regarded as the simplest of the so-called 'electron-deficient' molecules. Such molecules possess fewer electrons than those apparently required to fill all the bonding orbital's, based on the criterion that 
a normal bonding orbital involving two atoms contains two electrons. The molecular orbital bonding scheme for diborane has been discussed extensively (Lipscomb 1963). The compound with the highest gravimetric hydrogen density at room temperature known today is $\mathrm{LiBH}_{4}(18$ mass \%). Therefore, this complex hydride could be the ideal hydrogen storage material for mobile applications. $\mathrm{LiBH}_{4}$ desorbs three of the for hydrogen in the compound upon melting at $280^{\circ} \mathrm{C}$ and decomposes into $\mathrm{LiH}$ and boron. The desorption process can be catalyzed by adding $\mathrm{SiO}_{2}$ and significant thermal desorption was observed starting at $100^{\circ} \mathrm{C}$ (Züttel et al. 2003). Recently it has been shown, that the hydrogen desorption reaction is reversible and the end products lithiumhydride and boron absorb hydrogen at $690^{\circ} \mathrm{C}$ and 200 bar to form $\mathrm{LiBH}_{4}$ (Sudan and Züttel 2003). The scientific understanding of the mechanism of the thermal hydrogen desorption from $\mathrm{LiBH}_{4}$ and the absorption remains a challenge and more research work has to be carried out. Very little is known today about $\mathrm{Al}\left(\mathrm{BH}_{4}\right)_{3}$ a complex hydride with a very high gravimetric hydrogen density of 17 mass $\%$ and the highest known volumetric hydrogen density of $150 \mathrm{~kg} \mathrm{~m}^{-3}$ Almenningen et al. 1968). Furthermore, $\mathrm{Al}\left(\mathrm{BH}_{4}\right)_{3}$ has a melting point of $-65^{\circ} \mathrm{C}$ and is liquid at room temperature. Beside of the the covalent hydrocarbons, this is the only liquid hydride at room temperature.

\subsection{Chemical reaction with water}

Hydrogen can be generated from metals and chemical compounds reacting with water. The common experiment-shown in many chemistry classes-where a piece of sodium floating on water produces hydrogen, demonstrates such a process. The sodium is transformed to sodium hydroxide in this reaction. The reaction is not directly reversible but the sodium hydroxide could later be removed and reduced in a solar furnace back to metallic sodium. Two sodium atoms react with two water molecules and produces one hydrogen molecule. The hydrogen molecule produces again a water molecule in the combustion, which can be recycled to generate more hydrogen gas. However, the second water molecule necessary for the oxidation of the two sodium atoms has to be added. Therefore, sodium has a gravimetric hydrogen density of 3 mass $\%$. The same process carried out with lithium leads to a gravimetric hydrogen density of 6.3 mass \%. The major challenge with this storage method is the reversibility and the control of the thermal reduction process in order to produce the metal in a solar furnace. The process has been successfully demonstrated with zinc (Steinfeld 2002). The 1st, endothermic step is the thermal dissociation of $\mathrm{ZnO}(\mathrm{s})$ into $\mathrm{Zn}(\mathrm{g})$ and $\mathrm{O}_{2}$ at 2,300 K using concentrated solar energy as the source of process heat. The second, non-solar, exothermic step is the hydrolysis of $\mathrm{Zn}(\mathrm{l})$ at $700 \mathrm{~K}$ to form $\mathrm{H}_{2}$ and $\mathrm{ZnO}(\mathrm{s})$; the latter separates naturally and is recycled to the first step. Hydrogen and oxygen are derived in different steps, thereby eliminating the need for high-temperature gas separation. A 2nd law analysis performed on the closed cyclic process indicates a maximum energy conversion efficiency of $29 \%$ (ratio of $\Delta G\left(\mathrm{H}_{2}+0.5 \mathrm{O}_{2} \rightarrow \mathrm{H}_{2} \mathrm{O}\right.$ ) for the $\mathrm{H}_{2}$ produced to the solar power input), when using a solar cavity-receiver operated at 2,300 $\mathrm{K}$ and subjected to a solar flux concentration ratio of 5,000. The major sources of irreversibility are associated with the re-radiation losses from the solar reactor and the quenching of $\mathrm{Zn}(\mathrm{g})$ and $\mathrm{O}_{2}$ to avoid their recombination. An economic assessment for a large-scale chemical plant, having a solar thermal power input into the solar 
reactor of $90 \mathrm{MW}$ and a hydrogen production output from the hydrolyser of $61 \mathrm{GWh}$ year $^{-1}$, indicates that the cost of solar hydrogen ranges between 0.13 and $0.15 \$ \mathrm{kWh}^{-1}$ (based on its low heating value and a heliostat field cost at 100-150 $\$ \mathrm{~m}^{-2}$ ) and, thus, might be competitive vis-à-vis other renewables-based routes such as electrolysis of water using solar-generated electricity. The economic feasibility of the proposed solar process is strongly dependent on the development of an effective $\mathrm{Zn} / \mathrm{O}_{2}$ separation technique (either by quench or by in situ electrolytic separation) that eliminates the need for an inert gas.

\section{Conclusion}

The hydrogen revolution following the industrial age has just started. Hydrogen production, storage and conversion has reached a technological level although plenty of improvements and new discoveries are still possible. The hydrogen storage is often considered as the bottleneck of the renewable energy economy based on the synthetic fuel hydrogen. Six different hydrogen storage methods have been described. Among the well established high pressure cylinders for laboratory applications and the liquid hydrogen for air and space applications, metal hydrides and complex hydrides offer a very safe and efficient way to store hydrogen (Fig. 11). Further scientific research and technical developments will lead to new materials with a higher volumetric and gravimetric hydrogen density. The best materials today

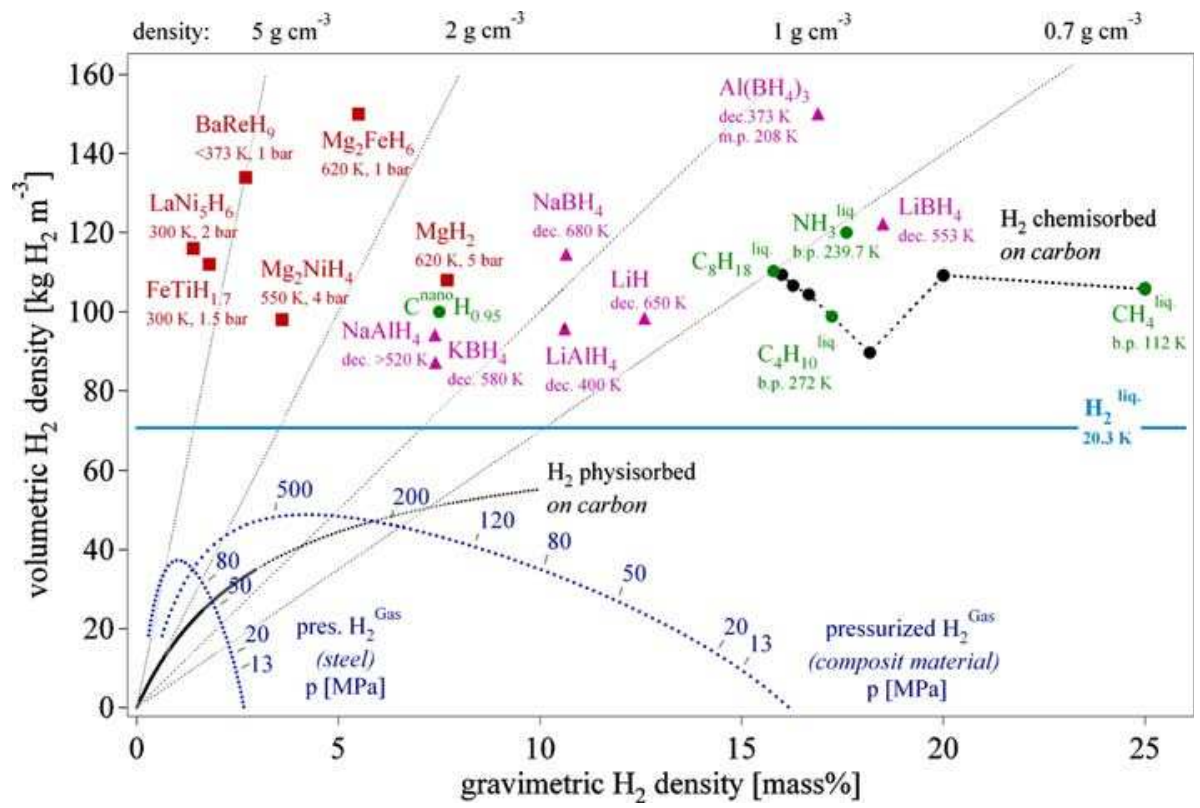

Fig. 11 Volumetric and gravimetric hydrogen density of some selected hydrides. $\mathrm{Mg}_{2} \mathrm{FeH}_{6}$ shows the highest known volumetric hydrogen density of $150 \mathrm{~kg} \mathrm{~m}^{-3}$, which is more than the double of liquid hydrogen. $\mathrm{BaReH}_{9}$ has the largest $\mathrm{H} / \mathrm{M}$ ratio of 4.5 , i.e. 4.5 hydrogen atoms per metal atom. $\mathrm{LiBH}_{4}$ exhibits the highest gravimetric hydrogen density of 18 mass\%. Pressurized gas storage is shown for steel (tensile strength $\sigma_{\mathrm{v}}=460 \mathrm{MPa}$, density $6,500 \mathrm{~kg} \mathrm{~m}^{-3}$ ) and a hypothetical composite material $\left(\sigma=1,500 \mathrm{MPa}\right.$, density $\left.3,000 \mathrm{~kg} \mathrm{~m}^{-3}\right)$ 
show a volumetric storage density of $150 \mathrm{~kg} \mathrm{~m}^{-3}$ which can be improved by approximately $50 \%$ according to theoretical estimations.

Acknowledgement This work was supported by the Swiss federal office of energy (Bundesamt für Energie, BfE) in contract with the International Energy Agency (IEA), the Swiss Federal Office of Education and Science (BBW), the European Commission and the Science Faculty of the University of Fribourg in Switzerland.

\section{References}

Abe A, Nakamura M, Sato I, Uetani H, Fujitani T (1998) Studies of the large-scale sea transportation of liquid hydrogen. Int J Hydrogen Energy 23(2):115-121

Almenningen A, Gundersen G, Haaland A (1968) On the molecular structure of aluminium borohydride $\mathrm{Al}\left(\mathrm{BH}_{4}\right)_{3}$. Acta Chem Scand 22:328-334

von Ardenne M, Musiol G, Reball S (1990) Effekte der Physik. Verlag Harry Deutsch, pp 712-715

Baltimore MD (1998) Health physics \& radiological health handbook, 3rd edn. Williams \& Wilkins, pp 6-11

Beebe RA, Biscoe J, Smith WR, Wendell CB (1947) Heats of adsorption on carbon black. J Am Chem Soc 69:95

Bogdanović B, Schwickardi M (1997) Ti-doped alkali metal aluminium hydrides as potential novel reversible hydrogen storage materials. J Alloys Comp 253-254:1-9

Bogdanović B, Brand RA, Marjanovic A, Schwickardi M, Tolle J (2000) Metal-doped sodium aluminium hydrides as potential new hydrogen storage materials. J Alloys Comp 302(1-2):36-58

Brunauer S, Emmett PH, Teller E (1938) Adsorption of gases in multimolecular layers. J Am Chem Soc 60:309

Bulletin (2000) Magazin der Eidgenössischen Technischen Hochschule Zürich. 276

Campbell NA (1996) Biology, 4th edn. Menlo Park, California USA, The Benjamin/Cummings Publishing Company Inc., ISBN: 0-8053-1940-9, pp 182-203

Chen G, Anghaie S (1992) Based on NASA/NIST databases, http://www.inspi.ufl.edu/data/ h_prop_package.html

Dillon AC, Jones KM, Bekkedahl TA, Kiang CH, Bethune DS, Heben MJ (1997) Storage of hydrogen in single-walled carbon nanotubes. Nature 386:377

DOE (2000) Dillon A.C. et al., Proceedings of the 2000 DOE/NREL hydrogen program review, May 8-10

Dymova TN, Eliseeva NG, Bakum SI, Dergachev YM (1974) Direct synthesis of aluminium hydrides of alkaline metals in melts. Dok Akad Nauk USSR 215:1369

Flynn TM (1992) A liquification of gases, McGraw-Hill encyclopedia of science \& technology, 7th edn. New York, McGraw-Hill, vol 10, pp 106-109

Fukai Y (1989) Site occupancy and phase stability of some metal hydrides. Z Phys Chem 164:165

Goerrig D (1958) Verfahren zur Herstellung von Boranaten. Ger Pat (Dec 27), 1,077,644

Gregg SJ, Sing KSW (1967) Adsorption, surface area and porosity. Academic Press, London

Griessen R, Riesterer T (1988) Heat of formation models. In: Schlapbach L (ed) Hydrogen in intermetallic compounds I electronic, thermodynamic, and crystallographic properties, preparation. Springer Series Topics in Applied Physics, vol 63, pp 219-284

GTec SA (2001) Product specification from GTec SA, rte de Clos-Donroux 1, CH-1870 Monthey, Switzerland

Hirscher M, Becher M, Haluska M, Dettlaff-Weglikowska U, Quintel GS, Duesberg A, Choi YM, Downes P, Hulman M, Roth S, Stepanek I, Bernier P (2001) Hydrogen storage in sonicated carbon materials. Appl Phys A 72:129

Huheey JE (1983) Inorganic chemistry. Harper \& Row, New York

Huston EL (1984) A liquid and solid storage of hydrogen. Proceedings of the 5th World Hydrogen Energy Conference, vol 3, July 15-20, 1984, Toronto, Canada

Irani RS (2002) Hydrogen storage: high-pressure gas containment. MRS Bulletin (September), pp 680-682

Lee SM, Park KS, Choi YC, Park YS, Bok JM, Bae DJ, Nahm KS, Choi YG, Yu SCh, Kim N, Frauenheim T, Lee YH (2000) Hydrogen adsorption and storage in carbon nanotubes. Synt Metals 113:209

空 Springer 
Lee SM, An KH, Lee YH, Seifert G, Frauenheim T (2001) Novel mechanism of hydrogen storage in carbon nanotubes. J Korean Phys Soc 38:686; Lee SM, Lee YH (2000) Hydrogen storage in single-walled carbon nanotubes. Appl Phys Lett 76:2879

Lennard-Jones JE (1932) Processes of adsorption and diffusion on solid surfaces. Trans Faraday Soc 28:333

Leung WB, March NH, Motz H (1976) Primitive phase diagram for hydrogen. Phys Lett 56A(6):425426

Lippard SJ, Ucko DA (1968) Transition metal borohydride complexes. II1. The reaction of copper(I) compounds with boron hydride anions. Inorg Chem 7:1051

Lipscomb WN (1963) Boron hydrides. Benjamin, New York

London F (1930) Zur theorie und systematik der molekularkräfte. Z Physik 63:245; Z Physik Chem 11:222

Ma Y, Xia Y, Zhao M, Wang R and Mei L (2001) Effective hydrogen storage in single-wall carbon nanotubes. Phys Rev B 63:115422

Müller WM, Blackledge IR and Libowitz GG (eds) (1968) Metal hydrides. Academic Press, New York

Nijkamp MG, Raaymakers JEMJ, van Dillen AJ, de Jong KP (2001) Hydrogen storage using physisorption-materials demands. Appl Phys A 72:619

Nützenadel Ch, Züttel A, Schlapbach L (1999) Electrochemical storage of hydrogen in nanotube materials. In: Huzmany H, Fink J, Mehring M, Roth S (eds) Electronic properties of novel materials science and technology of molecular nanostructures, chapt 9. American Institute of Physics, New York, p 462

Nützenadel Ch, Züttel A, Emmenegger Ch, Sudan P, Schlapbach L (2001) Electrochemical storage of hydrogen in carbon single wall nanotubes. In: Thorpe MF (ed) Sciences and applications of nanotubes. Kluwer Academic Publishing/Plenum Press, Fundamental Materials Research Series, Chapt. 10, p 205

Pearson GR (1985) The transition-metal-hydrogen bond. Chem Rev 85:41-49

Schlesinger HJ and Brown HC (1940) Metallo Borohydrides. III. Lithium Borohydride. J Am Chem Soc 62:3429-3435

Schlesinger HJ, Brown HC, Hoekstra HR, Rapp LR (1953) Reactions of Diborane with alkali metal hydrides and their addition compounds. New syntheses of Borohydrides. Sodium and Potassium Borohydrides. J Am Chem Soc 75:199-204

Schrauzer GN (1955) Über ein Peridensystem der Metallboranate. Naturwissenschaften 42:438

Steinfeld A (2002) Solar hydrogen production via a two-step water-splitting thermochemical cycle based on $\mathrm{Zn} / \mathrm{ZnO}$ redox reactions. Int J Hydrogen Energy 27:611-619

Steinfeld A, Palumbo R (2001) In: Meyers RA (ed) Solar thermochemical process technology. Encyclopedia of physical science and technology, Academic Press, vol 15, pp 237-256, ISBN $0-12-227410-5$

Sudan P, Züttel A (2003) Letter to Nature Materials (submitted)

Weast RC (1976) Handbook of chemistry and physics, 57th edn. CRC Press

Yvon K (1998) Complex transition metal hydrides. Chimia 52(10):613-619

Züttel A, Sudan P, Mauron Ph, Kyiobaiashi T, Emmenegger Ch, Schlapbach L (2002) Hydrogen sorption by carbon nanotubes and other carbon nanostructures. Int J Hydrogen Energy 27:203

Züttel A, Sudan P, Mauron Ph, Emmenegger Ch, Kiyobayashi T, Schlapbach L (2001) Hydrogen interaction with carbon nanostructures. J Metastable Nanocrystal Mat 11:95

Züttel A, Wenger P, Rensch S, Sudan P, Mauron P, Emmenegger C (2003) $\mathrm{LiBH}_{4}$ a new hydrogen storage material. J Power Sources 5194:1-7 